\title{
Conditions for Mutagenesis of the Nitrogen-fixing Cyanobacterium Anabaena variabilis
}

\author{
By JOHN S. CHAPMAN† AND JOHN C. MEEKS* \\ Department of Bacteriology, University of California, Davis, California 95616, USA
}

(Received 19 August 1986)

\begin{abstract}
Chemically induced mutation in the cyanobacterium Anabaena variabilis was studied using resistance to the pyrimidine analogue 5'-fluorocytosine as a genetic marker which can be selected positively. Cytosine is metabolized through uracil and the UMP pyrophosphorylase 'salvage' pathway in this photoautotroph, as it is in enteric bacteria. Treatment with various concentrations of $N$-methyl- $N$ '-nitro- $N$-nitrosoguanidine (MNNG) gave the highest frequencies of 5FC-resistant mutants when lethality approximated $99 \%$, irrespective of the exposure time or mutagen concentration. The $\mathrm{pH}$ of the incubation medium strongly influenced mutation; exposure to MNNG at pH 6.0 yielded 13-fold higher frequencies of mutants than at $\mathrm{pH} 7 \cdot 5$. The greatest frequency of resistant cells was found after cultures had undergone six or more doublings following mutagenesis. The mutation frequencies obtained by treatment with MNNG were approximately 4- and 25-fold higher than those after exposure under empirically defined conditions to diethyl sulphate or nitrous acid, respectively, and $1.4 \times 10^{3}$-fold higher than the frequency of spontaneous mutation. Neither chloramphenicol-inhibited nor caffeinesensitive systems capable of repairing MNNG-induced DNA damage were observed.
\end{abstract}

\section{INTRODUCTION}

Progress in the area of physiological genetics of the cyanobacteria has been lacking, in part due to difficulties in isolating specific mutants (Herdman, 1982) for subsequent genetic analysis by transformation (Buzby et al., 1983) or conjugation (Wolk et al., 1984). Studies on the optimal conditions for the generation of mutants have been undertaken for the unicellular cyanobacteria Anacystis nidulans (syn. Synechococcus leopoliensis, Rippka et al., 1979) (Herdman \& Carr, 1972; Herdman et al., 1980) and Aphanocapsa sp. strain 6714 (Astier et al., 1979), as well as the filamentous cyanobacterium Plectonema boryanum (Singh \& Kashyap, 1977). Although auxotrophic (Currier et al., 1977), photosynthetic (Shaffer et al., 1978) and analogue-resistant (Chapman \& Meeks, 1983) mutants of a heterocyst-forming cyanobacterium have been reported, there have been no systematic studies of mutagenesis in these organisms.

The heterocyst-forming cyanobacteria present an experimental system useful for studying the processes of cellular differentiation, $\mathrm{N}_{2}$ fixation, and, in some strains, symbiotic association. We chose to examine parameters of mutagenesis using Anabaena variabilis because it has a high plating efficiency (Wolk \& Wojciuch, 1973) and a limited range of mutants have been isolated (Currier et al., 1977). Herein we define optimal conditions for mutagenesis of $A$. variabilis using $N$-methyl- $N^{\prime}$-nitro- $N$-nitrosoguanidine (MNNG) as the mutagen and a positive selection for resistance to the analogue $5^{\prime}$-fluorocytosine $(5 \mathrm{FC})$ as the indicator of mutagenic effectiveness. The mutagenic activities of diethyl sulphate (DES) and nitrous acid were also compared under empirically defined conditions.

† Present address: Hoffman-LaRoche, Inc., Roche Research Center, Nutley, New Jersey 07110, USA.

Abbreviations: DES, diethyl sulphate; 5FC, 5'-fluorocytosine; 5FU, 5'-fluorouracil; MNNG, $N$-methyl- $N^{\prime}$ nitro- $N$-nitrosoguanidine. 


\section{METHODS}

Strains and culture conditions. Anabaena variabilis Kütz. (ATCC 29413) and its uracil-requiring mutant U2 were gifts from C. P. Wolk. The strains were cultured in the basal medium of Allen \& Arnon (1955). The basal medium was used at full strength when solidified with $1 \%(\mathrm{w} / \mathrm{v})$ purified agar or diluted eightfold for growth in liquid culture. Agar was purified by the method of Braun \& Wood (1962). The medium for mutant U2 was supplemented with $0.04 \mathrm{~mm}$-uracil. The cultures were incubated at $30^{\circ} \mathrm{C}$ under light $\left(8.4 \mathrm{~W} \mathrm{~m}^{-2}\right)$ from cool-white fluorescent lamps; liquid cultures were placed on an orbital shaker at 100 r.p.m. The cultures were routinely checked for contamination microscopically and by plating onto nutrient agar. Cell numbers were determined microscopically using a haemocytometer, and viable c.f.u. were determined by serial dilution and plating.

Mutagenesis. Since a c.f.u. of a filamentous organism is equivalent to the total number of cells in a filament rather than a single cell, cultures of $A$. variabilis in the exponential phase of growth $\left(10^{6}-10^{7} \mathrm{cells}^{-1}\right.$ in $50 \mathrm{ml}$ volumes) were fragmented by cavitation in a sonic cleaning bath to reduce the filaments to an average length of two cells (Wolk \& Wojciuch, 1973). This procedure provides a more accurate determination of the viable cell number. However, the plating efficiency of fragmented cultures decreased from $99.8 \%$ on medium supplemented with ammonium to $72 \%$ in the absence of combined nitrogen, apparently because some single-celled filaments exhausted their internal supply of nitrogen before they reached the critical length required for heterocyst differentiation (Wilcox et al., 1975). For reasons of quantification, the basal medium was always supplemented with $2.5 \mathrm{mM}-\mathrm{NH}_{4} \mathrm{Cl}$ and buffered with $5 \mathrm{~mm}$-TES or $5 \mathrm{~mm}$-MOPS (Sigma), both adjusted to pH $7.5 \mathrm{with} \mathrm{NaOH}$.

The fragmented cultures were washed twice with basal medium and suspended at a concentration of $10^{6}$ to $2 \times$ $10^{7}$ cells $\mathrm{ml}^{-1}$ in a $20 \mathrm{ml}$ volume for exposure to the mutagen. The mutagen was removed by three centrifugal washes $(1000 \mathrm{~g}, 5 \mathrm{~min})$ with basal medium and the treated cultures were suspended in buffered ammonium basal medium.

Stock solutions of MNNG at $10 \mathrm{mg} \mathrm{ml}^{-1}$ were made in glass-distilled water by heating to $45^{\circ} \mathrm{C}$ followed by mild cavitation in a sonic cleaning bath to complete solubilization. The stock solution was filter sterilized and $2.0 \mathrm{ml}$ samples were frozen until use and then never refrozen. Various exposure times ( 5 min to $6 \mathrm{~h}$ ) and MNNG concentrations $(0.025-1.0 \mathrm{mg}$ per $\mathrm{ml}$ of cell suspension) were examined. In experiments to determine the $\mathrm{pH}$ optimum for MNNG mutagenesis, the fragmented cultures were suspended in either 10 mM-citrate buffer $\mathrm{pH} 5 \cdot 0$, $5 \cdot 5$ or $6 \cdot 0$, or $10 \mathrm{~mm}$-TES buffer $\mathrm{pH} 6 \cdot 5,7 \cdot 0$ or $7 \cdot 5$.

DES (Sigma) was used as supplied, generally at $5 \mu \mathrm{l}$ per $\mathrm{ml}$ of cell suspension in $20 \mathrm{ml}$ buffered ammonium basal medium, $\mathrm{pH} 7 \cdot 5$. Various exposure times up to $30 \mathrm{~min}$ and concentrations from 2.5 to $30 \mu \mathrm{l}$ per $\mathrm{ml}$ of cell suspension were also examined.

For nitrous acid treatment, fragmented cultures were suspended in $13 \mathrm{ml} 0.6 \mathrm{M}$-acetate buffer, $\mathrm{pH} 4.5$, to which an equal volume of $0.05 \mathrm{M}$-sodium nitrite was added. At various times, treatment was terminated by adding $5.0 \mathrm{ml}$ samples to $37 \mathrm{ml}$ of $0.067 \mathrm{M}$-phosphate buffer $\mathrm{pH} 8 \cdot 0$.

The survivors were screened for resistance to $0.3 \mathrm{~mm}-5 \mathrm{FC}$ or 5 -fluorouracil (5FU; US Biochemical Corp.) on solid media (4-10 plates with $200 \mu$ l of suspension per plate), generally after $6 \mathrm{~d}$ culture in buffered liquid ammonium basal medium following mutagenesis. In two experiments to determine mutation frequency $1-3 \mathrm{~d}$ after exposure to $\mathrm{MNNG}$, approximately $10^{-7}$ cells ml-1 in $200 \mathrm{ml}$ were treated and correspondingly higher numbers of cells plated on $5 \mathrm{FC}$ medium.

Enzyme assay. Cytosine deaminase activity was determined with cells made permeable with toluene using a protocol adapted from Stacey et al. (1979). A $2.0 \mathrm{ml}$ suspension of $A$. variabilis containing approximately $10^{10}$ cells $\mathrm{ml}^{-1}$ was mixed with $0.5 \mathrm{ml}$ toluene, incubated at room temperature for $5 \mathrm{~min}$ in a $15 \mathrm{ml}$ conical centrifuge tube, centrifuged $(1000 \mathrm{~g}, 5 \mathrm{~min})$ and suspended in $0.8 \mathrm{ml}$ basal medium. The cytosine deaminase assay was adapted from Neuhard \& Ingraham (1968) and contained in a final volume of $1.0 \mathrm{ml}: 50 \mathrm{~mm}$-Tris/ $/ \mathrm{HCl}$ buffer, $\mathrm{pH} 7 \cdot 0$, $1 \mathrm{~mm}$-cytosine, and $0.8 \mathrm{ml}$ of cells. The reaction was initiated by the addition of toluene-treated cells and terminated at $30 \mathrm{~min}$ intervals by transferring $0.1 \mathrm{ml}$ samples to $0.9 \mathrm{ml}$ cold $0.5 \mathrm{M}$-perchloric acid. The acidtreated samples were centrifuged $(1000 \mathrm{~g}, 5 \mathrm{~min})$ and the absorbance of the supernatant solutions was measured at $282 \mathrm{~nm}$. An absorbance change of 0.208 units was equivalent to a change in cytosine concentration of $250 \mathrm{nmol}$. Activity was normalized to cellular chlorophyll $a$ content, determined as before (Chapman \& Meeks, 1983).

\section{RESULTS AND DISCUSSION}

\section{Characteristics of the resistance marker}

The growth of wild-type $A$. variabilis was inhibited by $0.3 \mathrm{~mm}$ concentrations of either $5 \mathrm{FC}$ or 5FU. In enteric bacteria, resistance to 5FC can occur through the inactivation of either cytosine deaminase (EC 3.5.4.1) or UMP pyrophosphorylase (EC 2.4.2.9) (Beck et al., 1972). Cells lacking UMP pyrophosphorylase are resistant to both $5 \mathrm{FC}$ and $5 \mathrm{FU}$, while those lacking cytosine deaminase are resistant to $5 \mathrm{FC}$ only. Of 100 randomly chosen mutants resistant to $5 \mathrm{FC}$, 


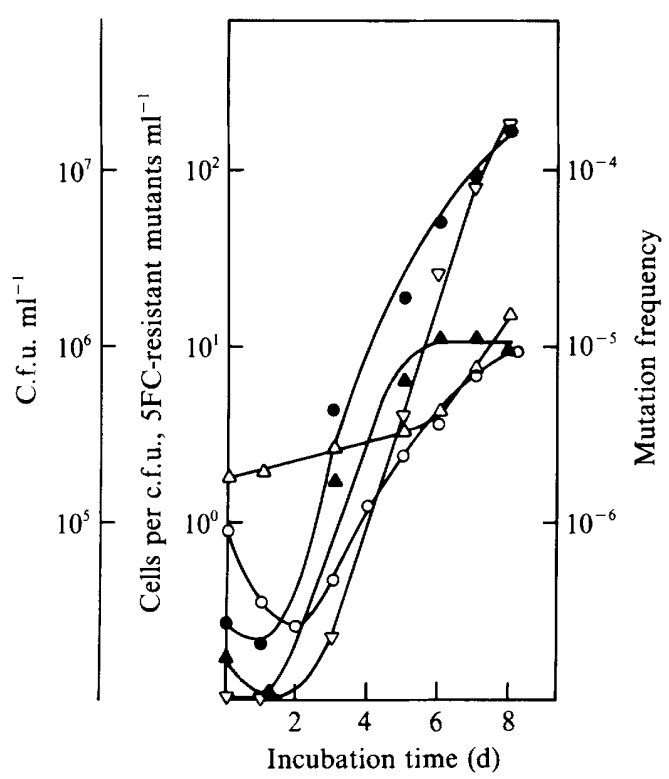

Fig. 1. Appearance of 5FC-resistant cells in populations of A. variabilis, and changes in viability, after treatment of cavitated suspensions with $0.025 \mathrm{mg} \mathrm{MNNG} \mathrm{ml}^{-1}$ at $\mathrm{pH} 7.0$ for $6 \mathrm{~h}$. Samples were removed daily and the number of cells per c.f.u. $(\triangle)$, c.f.u. $\mathrm{ml}^{-1}(\mathrm{O})$, and $5 \mathrm{FC}$-resistant mutants $\mathrm{ml}^{-1}$ $(\nabla)$ were determined. From these values the mutation frequencies per c.f.u. $(\Theta)$ and per cell $(\Delta)$ were calculated. The values plotted represent means of three to five separate experiments.

Table 1. Cytosine deaminase activity of wild-type and mutant strains of A. variabilis

$\begin{array}{lccc}\text { Strain } & \text { 5FC-resistance } & \text { 5FU-resistance } & \text { Specific activity* } \\ \text { Wild-type } & - & - & 74.9 \pm 7.8 \\ \text { 5FC-4 } & + & - & 8.8 \pm 0.24 \\ \text { 5FC-6 } & + & + & 73.8 \pm 2.5\end{array}$

${ }^{*}$ Expressed as $\mathrm{nmol} \mathrm{min}^{-1}(\mathrm{mg} \text { chlorophyll } a)^{-1}$; values represent the means \pm SE of four experiments.

isolated and selected as described below, 54 were also resistant to $5 \mathrm{FU}$. A representative mutant resistant only to $5 \mathrm{FC}$ had $12 \%$ of the cytosine deaminase activity of the wild-type (Table 1 ). Conversely, a mutant resistant to both $5 \mathrm{FC}$ and $5 \mathrm{FU}$ had a cytosine deaminase activity identical to the wild-type (Table 1).

Currier \& Wolk (1978) showed that the enzymes for de novo synthesis of uridylic acid, as described for enteric bacteria (O'Donovan \& Neuhard, 1970), are present in $A$. variabilis. They assumed that the uracil-dependent growth of mutants of $A$. variabilis that lack the first enzyme of the pathway, aspartate transcarbamylase, resulted from the activity of UMP pyrophosphorylase. The sensitivity of wild-type $A$. variabilis to $5 \mathrm{FU}$ and subsequent isolation of $5 \mathrm{FU}$-resistant mutants are consistent with, but do not prove, the presence of such a 'salvage' enzyme. The measured activity of cytosine deaminase, sensitivity to $5 \mathrm{FC}$, and isolation of mutants resistant to $5 \mathrm{FC}$ but sensitive to 5FU, all imply that cytosine is metabolized through uracil as in Salmonella typhimurium (Beck et al., 1972). This conclusion is supported by the observation that the $\boldsymbol{A}$. variabilis uracil-requiring mutant U2 (Currier et al., 1977) grew equally well when uracil was replaced by cytosine (data not shown).

\section{Segregation of mutant genomes}

To establish an optimal time for genomic segregation after MNNG mutagenesis, the numbers of 5FC-resistant mutants $\mathrm{ml}^{-1}$, cells per filament and c.f.u. $\mathrm{ml}^{-1}$ were determined daily (Fig. 1). 
Table 2. Effect of $p H$ of the suspension medium on $M N N G$-induced mutation frequencies in A. variabilis

Cultures were exposed to $1.0 \mathrm{mg} \mathrm{MNNG} \mathrm{ml} \mathrm{m}^{-1}$ for $15 \mathrm{~min}$ and subsequently grown in liquid medium for $6 \mathrm{~d}$ before determination of mutation frequencies. The values represent the means \pm SE of four to six experiments.

\begin{tabular}{ll} 
& \multicolumn{2}{c}{ Frequency of } \\
pH & 5FC-resistant mutants \\
5.0 & $(0.446 \pm 0.13) \times 10^{-4}$ \\
5.5 & $(1.48 \pm 0.58) \times 10^{-4}$ \\
6.0 & $(3.98 \pm 1.00) \times 10^{-4}$ \\
6.5 & $(1.18 \pm 0.90) \times 10^{-4}$ \\
7.0 & $(0.943 \pm 0.09) \times 10^{-4}$ \\
7.5 & $(0.30 \pm 0.02) \times 10^{-4}$
\end{tabular}

Colonies resistant to 5FC did not appear in numbers greater than predicted from the spontaneous rate of mutation until the liquid suspensions had been cultured for $3 \mathrm{~d}$ after mutagenesis. The total numbers of 5FC-resistant mutants increased for at least $8 \mathrm{~d}$, as did the mutation frequency normalized to c.f.u. However, when normalized to total cells, the maximal frequency appeared to be reached by day 6 . This discrepancy in normalized values results from the opposing processes of cellular division and lysis discussed below. A segregation period of $6 \mathrm{~d}$ was used in subsequent experiments, although for convenience mutation frequency was calculated per c.f.u.

The number of c.f.u. continued to decrease after mutagenesis until after $2 \mathrm{~d}$ only $36 \%$ of the c.f.u. which were present immediately after mutagenesis remained. Between 2 and $6 \mathrm{~d}$ after mutagenesis the number of c.f.u. increased 14-fold. This growth response is unusual considering the filamentous nature of $A$. variabilis; one might predict an increase in cell number but this would not correspond to an increase in c.f.u. It took $4 \mathrm{~d}$ from the time of mutagenesis for a filament to double its length and the average filament length began to increase at the same time as the number of c.f.u. began to stabilize. This implies that continued lysis of newly formed daughter cells resulted in filament breakage and the subsequent increase in c.f.u. The competing variables of cellular division and cellular lysis in mutagenized cultures precluded calculations of the actual growth rate of $A$. variabilis under these conditions, although the density of the cultures was seen to increase. Batch cultures of wild-type cells had a doubling time of 20-24 h under identical growth conditions (data not shown). Thus, we assume that the $3 \mathrm{~d}$ culture period before increased numbers of 5FC-resistant mutants were detected corresponded to approximately three doublings and would reflect the segregation of five to eight copies of the genome per cell of $A$. variabilis. Genome multiplicity of this order, or greater, is not unusual in cyanobacteria (Doolittle, 1979).

\section{$M N N G$-induced mutagenesis}

The frequency of spontaneous $5 \mathrm{FC}$-resistant mutants, determined by plating fragmented cultures directly onto $5 \mathrm{FC}$ plates, was $2.8 \times 10^{-7} \pm 1.7 \times 10^{-7}$ per c.f.u. (mean of three experiments \pm SE). The average size of a c.f.u. in these experiments was $1.6 \pm 0.2$ cells.

The effects of three parameters on MNNG-induced mutation to 5FC resistance were examined: duration of exposure, $\mathrm{pH}$ of the suspension medium, and concentration of the mutagen. The viability and mutation frequency of $A$. variabilis after treatment with MNNG at $1.0 \mathrm{mg} \mathrm{ml}^{-1}$ at $\mathrm{pH} 6.0$ and 7.0 for various periods are shown in Fig. 2(a). A 75\% reduction in viable c.f.u. occurred at either $\mathrm{pH}$ within $5 \mathrm{~min}$ of exposure and reached $99.9 \%$ by $30 \mathrm{~min}$. The maximal mutation frequency at $\mathrm{pH} 7.0$ was observed after $20 \mathrm{~min}$ of exposure and corresponded to $>99 \%$ lethality. A similar pattern of lethality and mutation frequency was seen at $\mathrm{pH} 6 \cdot 0$. The optimal $\mathrm{pH}$ for MNNG-induced mutageneis of $A$. variabilis was 6.0 (Table 2). The mutation frequency at $\mathrm{pH} 6.0$ was more than 4- and 13-fold higher than the frequencies of cultures exposed at $\mathrm{pH} 7 \cdot 0$ and 7.5 respectively. 


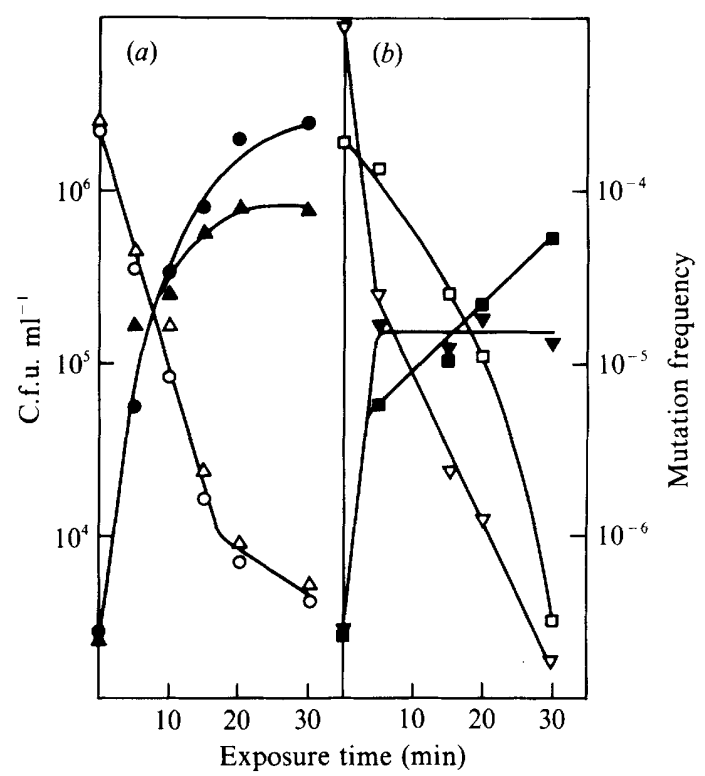

Fig. 2. Effect of MNNG (a), DES $(b)$, and nitrous acid (b) on the viability (c.f.u.) and frequency of $5 F C$ resistant mutants (per c.f.u.) in cultures of $A$. variabilis as a function of exposure time. For MNNG treatments $\left(1.0 \mathrm{mg} \mathrm{ml}^{-1}\right)$, the cavitated suspensions were suspended in buffered ammonium basal medium at $\mathrm{pH} 7.0(\triangle, \Delta)$ or $10 \mathrm{~mm}$-citrate buffer at $\mathrm{pH} 6.0(\mathrm{O}, \boldsymbol{O})$. The cavitated samples for treatment with $5 \mu \mathrm{l} \mathrm{DES} \mathrm{ml} \mathrm{m}^{-1}(\square, \square)$ were suspended in buffered ammonium medium, while those for exposure to nitrous acid $(\nabla, \boldsymbol{\nabla})$ were suspended as described in Methods. At the noted times, samples were removed, washed or inactivated (nitrous acid) and suspended in buffered ammonium basal medium. Samples were immediately plated to determine c.f.u. $\mathrm{ml}^{-1}$ (open symbols); mutation frequencies (closed symbols) were determined after $6 \mathrm{~d}$ growth in liquid culture. The numbers represent means of four (MNNG at pH 6.0 and 7.0, and nitrous acid) or three (DES) separate experiments; the SES were less than $10 \%$ of the recorded values.

The shapes of the curves depicting viability and mutation frequency at $\mathrm{pH} 6.0$ with 0.025 and $0.250 \mathrm{mg} \mathrm{MNNG} \mathrm{ml}^{-1}$ (data not shown) were similar to those at $1.0 \mathrm{mg} \mathrm{ml}^{-1}$ (Fig. 2a). The maximum mutation frequencies obtained in these experiments were, in order of increasing MNNG concentration, $1.5 \times 10^{-4}, 1.2 \times 10^{-4}$ and $2.4 \times 10^{-4}$. These frequencies resulted only when lethality approached $99 \%$ (exposure times of 6,4 and $0.5 \mathrm{~h}$ with respect to increasing MNNG concentration).

The physiological response of $A$. variabilis to MNNG-induced mutation was similar to that of heterotrophic bacteria such as Escherichia coli (Adelberg et al., 1965) and Haemophilus influenzae (Kimball \& Setlow, 1974) only with respect to the optimal pH during incubation. This similarity is probably a consequence of the increased stability of MNNG at acid compared to alkaline $\mathrm{pH}$. In $A$. variabilis, maximal mutation frequencies were obtained when lethality approached $99 \%$, irrespective of the MNNG concentration or exposure time. Comparable results at higher $\mathrm{pH}$ were obtained by others for A. variabilis (Currier et al., 1977), Agmenellum quadruplicatum (Stevens \& van Baalen, 1969), and Anacystis nidulans (Herdman \& Carr, 1972). However, in E. coli there is no direct correlation between lethality and mutation; rather, maximal mutation frequencies occur at survival values between 43 and $75 \%$ of the initial population (Adelberg $e t$ al., 1965). There is no current biochemical information to explain the dramatic difference between cyanobacteria and $E$. coli with respect to the lethal and mutagenic effects of MNNG.

\section{Experiments with additional mutagens}

DES is an alkylating agent with a mode of action similar to that of MNNG (Bautz \& Freese, 1960). The number of c.f.u. of $A$. variabilis was reduced by $99.8 \%$ within $30 \mathrm{~min}$ of exposure to 
Table 3. Effects of caffeine and chloramphenicol (CAM) on MNNG-induced mutation frequencies and c.f.u. of $A$. variabilis

Mutagenesis was performed on fragmented cultures using $0.25 \mathrm{mg} \mathrm{MNNG} \mathrm{m}^{-1}$ for a $4 \mathrm{~h}$ exposure at $\mathrm{pH}$ 6.0. Samples were removed, washed twice, and suspended in buffered ammonium medium with or without $0.2 \mathrm{mg}$ caffeine or $0.005 \mathrm{mg} \mathrm{CAM} \mathrm{ml}^{-1}$; these compounds were removed by centrifugal washing after $6 \mathrm{~d}$ (caffeine) and after 2 or $6 \mathrm{~d}(\mathrm{CAM})$ and the cultures were suspended in fresh buffered ammonium medium. The numbers of c.f.u. $\mathrm{ml}^{-1}$ and mutation frequency were determined $6 \mathrm{~d}$ after mutagenesis. All values represent means $\pm S E$ of three (CAM) or four (caffeine) separate experiments.

$\begin{array}{lcc}\text { Treatment } & \text { C.f.u. } \mathrm{m}^{-1} & \begin{array}{c}\text { Frequency of } \\ \text { 5FC-resistant mutants }\end{array} \\ \text { No caffeine } & (4.9 \pm 0.6) \times 10^{5} & (1.36 \pm 0.9) \times 10^{-4} \\ \text { +Caffeine } & (4.0 \pm 1.6) \times 10^{5} & (1.12 \pm 0.8) \times 10^{-4} \\ \text { No CAM } & (1.7 \pm 0.6) \times 10^{6} & (2.3 \pm 1.9) \times 10^{-4} \\ \text { +CAM, d } & (1.6 \pm 1.2) \times 10^{6} & (1.1 \pm 0.6) \times 10^{-4} \\ \text { +CAM, 6 d } & (0.8 \pm 0.1) \times 10^{6} & (0.8 \pm 0.2) \times 10^{-4}\end{array}$

$5 \mu \mathrm{l}$ DES per $\mathrm{ml}$ of cell suspension (Fig. $2 b$ ). The frequency of $5 \mathrm{FC}$-resistant mutants increased with time of exposure up to $30 \mathrm{~min}$. Increasing the concentration of DES to $20 \mu \mathrm{ml}^{-1}$ resulted in a doubling of the mutation frequency relative to treatment with $5 \mu \mathrm{ml}^{-1}$ but at similar lethalities. The maximal mutation frequency produced by exposure to $20 \mu \mathrm{l} \mathrm{DES} \mathrm{ml} \mathrm{I}^{-1}$ was $0.98 \times 10^{-4}$. However, at this concentration droplets of the compound were visible in the medium, indicating saturation of the medium and implying that the most effective concentration of DES was between 5 and $20 \mu \mathrm{l}$ per $\mathrm{ml}$ of cell suspension.

A 5 min treatment of $A$. variabilis with $0.05 \mathrm{M}$-nitrous acid resulted in a $98 \%$ reduction in c.f.u. and a mutation frequency of $1.5 \times 10^{-5}$ (Fig. $2 b$ ). Increasing the time of exposure caused a decrease in viable c.f.u., but had little or no effect on the mutation frequency.

While substantially higher mutation frequencies were obtained with MNNG and DES, these agents tend to produce closely linked multiple mutations (Guerola et al., 1971). The mutagenic activity of nitrous acid in causing AT to GC transitions is more likely to result in single-site lesions (Zimmerman, 1977). This, and the observation that nitrous acid can induce mutations in cyanobacteria at a frequency approximately 54-fold higher than the spontaneous rate, indicates that more useful mutants may be generated by nitrous acid than by MNNG or DES.

\section{Effects of chloramphenicol and caffeine on mutation frequency}

The unicellular cyanobacterium Anacystis nidulans (Delaney \& Carr, 1975), as well as E. coli (Kato, 1977), have postreplication repair systems active after UV- or ethylmethane sulphonateinduced chromosomal damage that are inhibited by caffeine. Treatment with caffeine, at $200 \mu \mathrm{g} \mathrm{ml}^{-1}$, reduced the viability of $A$. variabilis cells that survived exposure to MNNG by about $20 \%$, but did not increase the mutation frequency (Table 3 ).

Chloramphenicol, at low concentrations $\left(2.5 \mu \mathrm{g} \mathrm{ml}^{-1}\right)$, enhances both UV- (Kato, 1977) and MNNG- (Sklar, 1978) stimulated mutation frequencies in $E$. coli by preventing the induced synthesis of repair enzymes. The presence of up to $5 \mu \mathrm{g}$ chloramphenicol ml${ }^{-1}$ during the entire $6 \mathrm{~d}$ segregation period after exposure to MNNG lowered both viability and mutation frequency of $A$. variabilis (Table 3 ). Removal of chloramphenicol $2 \mathrm{~d}$ after mutagenesis had no detectable effect on either the number of c.f.u. or the mutation frequency.

The apparent lack of a caffeine-sensitive or inducible repair system capable of affecting MNNG-induced lesions in $A$. variabilis does not exclude the presence of other types of repair systems. A variety of repair systems have been reported in cyanobacteria (Stevens \& van Baalen, 1969; Tang \& Asato, 1978).

The results of this study indicate that mutant phenotypes of a heterocyst-forming cyanobacterium can be recovered in high frequencies from the cells surviving chemical mutagenesis. Irrespective of the chemical mutagen, the incubation time following exposure and prior to selection or counterselection must allow for sufficient cell doublings to segregate 
multiple copies of the genome. The major problem confronting physiological genetic studies in cyanobacteria is not mutation, but selection of the desired mutant. For example, we have shown that the structural gene for the enzyme glutamine synthetase can be altered at high frequency (Chapman \& Meeks, 1983), but we (and others) have consistently failed to isolate mutants requiring glutamine, in direct selections or after counterselection (Chapman, 1984). This conclusion is supported by the fact that only a limited number of cyanobacterial mutants have been described that are auxotrophic for organic metabolites (Herdman, 1982).

This work was supported by the California Agriculture Experiment Station project number CAD*-3620-H, the National Science Foundation grants PCM 79-04136 and 83-16384, and the US Department of Agriculture Competitive Research Grants Program grant 79-39-2063-1-1-276-1.

\section{REFERENCES}

Adelberg, E. A., Mandel, M. \& Chen, G. C. (1965). Optimal conditions for mutagenesis by $N$-methyl- $N^{\prime}$ nitro- $N$-nitrosoguanidine in Escherichia coli. Biochemical and Biophysical Research Communications 18, 788-795.

Allen, M. B. \& ARnon, D. I. (1955). Studies on nitrogen-fixing blue-green algae. I. Growth and nitrogen fixation by Anabaena cylindrica Lemm. Plant Physiology 30, 366-372.

Astier, C., Joset-Espardellier, F. \& Meyer, I. (1979). Conditions for mutagenesis in the cyanobacterium Aphanocapsa 6714. Influence of repair phenomena. Archives of Microbiology 120, 93-96.

BaUtz, E. \& FreEse, E. (1960). In vivo action of alkylating mutagens. Proceedings of the National Academy of Sciences of the United States of America 46, $1585-1594$.

Beck, C. F., Ingraham, J. I., Neuhard, J. \& Thomassen, E. (1972). Metabolism of pyrimidines and pyrimidine nucleosides by Salmonella typhimurium. Journal of Bacteriology 110, 219-228.

Braun, A. C. \& WoOD, H. N. (1962). On the activation of certain essential biosynthetic systems in cells of Vinca rosea. Proceedings of the National Academy of Sciences of the United States of America 48, 17761782.

Buzby, J. S., Porter, R. D. \& Stevens, S. E., JR (1983). Plasmid transformation in Agmenellum quadruplicatum PR-6: construction of biphasic plasmids and characterization of their transformation properties. Journal of Bacteriology 154, 1446-1450.

Chapman, J. S. (1984). Parameters influencing the isolation of auxotrophs of Anabaena variabilis. $\mathrm{PhD}$ thesis, University of California, Davis, USA.

Chapman, J. S. \& MeEks, J. C. (1983). Glutamine and glutamate transport by Anabaena variabilis. Journal of Bacteriology 156, 122-129.

CURrier, T. C. \& WolK, C. P. (1978). Regulation of uridylic acid biosynthesis in the cyanobacterium Anabaena variabilis. Journal of Bacteriology 136, 682687.

Currier, T. C., Haury, J. F. \& Wolk, C. P. (1977). Isolation and characterization of auxotrophs of a filamentous cyanobacterium. Journal of Bacteriology 129, 1556-1562.

Delaney, S. F. \& CarR, N. G. (1975). Temporal genetic mapping in the blue-green alga Anacystis nidulans using ethylmethane sulphonate. Journal of General Microbiology 88, 259-268.
Doolitrle, W. F. (1979). The cyanobacterial genome, its expression and the control of that expression. Advances in Microbial Physiology 20, 1-102.

Guerola, N., Ingraham, J. L. \& Cerda-Olmedo, E. (1971). Induction of closely linked multiple mutation by $N$-methyl- $N^{\prime}$-nitro- $N$-nitrosoguanidine. Nature New Biology 230, 122-125.

Herdman, M. (1982). Evolution and genetic properties of cyanobacterial genomes. In The Biology of Cyanobacteria, pp. 263-305. Edited by N. G. Carr \& B. A. Whitton. Oxford: Blackwell Scientific Publications.

Herdman, M. \& CARR, N. G. (1972). The isolation and characterization of mutant strains of the blue-green alga Anacystis nidulans. Journal of General Microbiology 70, 213-220.

Herdman, M., Delaney, S. F. \& Carr, N. G. (1980). Mutation of the cyanobacterium Anacystis nidulans (Synechococcus PCC 6301): improved conditions for the isolation of auxotrophs. Archives of Microbiology 124, 177-184.

KaTO, T. (1977). Effects of chloramphenicol and caffeine on postreplication repair in $u v r A^{-} u m u C^{-}$ and $\mathrm{uvrA}^{-} \mathrm{recF}^{-}$strains of Escherichia coli $\mathrm{K} 12$. Molecular and General Genetics 156, 115-120.

Kimball, R. F. \& Setlow, J. K. (1974). Mutation fixation in MNNG-treated Haemophilus influenzae as determined by transformation. Mutation Research 22, $1-14$.

Neuhard, J. \& Ingraham, J. L. (1968). Mutants of Salmonella typhimurium requiring cytosine or cytidine for growth. Journal of Bacteriology 95, 24312434.

O'Donovan, G. A. \& Neuhard, J. (1970). Pyrimidine metabolism in microorganisms. Bacteriological Reviews 34, 278-343.

RipPKa, R., Deruelles, J., Waterbury, J., HerdMAN, M. \& STANIER, R. (1979). Generic assignments, strain histories and properties of pure cultures of cyanobacteria. Journal of General Microbiology 111, $1-61$.

Shaffer, P. W., Lockau, W. \& Wolk, C. P. (1978). Isolation of mutants of the cyanobacterium, Anabaena variabilis, impaired in photoautotrophy. Archives of Microbiology 117, 215-219.

Singh, R. N. \& KashyaP, K. N. (1977). Induction of mutations in the blue-green alga Plectonema boryanum. Mutation Research 43, 37-44.

SKLAR, R. (1978). Enhancement of nitrosoguanidine 
mutagenesis by chloramphenicol in Escherichia coli K12. Journal of Bacteriology 136, 460-462.

Stacey, G., van BaAlen, C. \& Tabita, F. R. (1979). Nitrogen and ammonia assimilation in the cyanobacteria: regulation of glutamine synthetase. Archives of Biochemistry and Biophysics 194, 457-467.

Stevens, S. E., JR \& van BaAlen, C. (1969). $N$-methyl$N$ 'nitro- $N$-nitrosoguanidine as a mutagen for bluegreen algae: evidence for repair. Journal of Phycology 5, 136-139.

TANG, T. \& Asato, Y. (1978). Ultraviolet light induction and photoreactivation of thymine dimers in Anacystis nidulans. Archives of Microbiology 119, 193-197.

Wilcox, M., Mitchison, G. J. \& Sмith, R. J. (1975). Spatial control of differentiation in the blue-green alga Anabaena cylindrica. In Microbiology - 1975, pp. 453-463. Edited by D. Schlessinger. Washington, DC: American Society for Microbiology.

Wolk, C. P. \& WoJciuch, E. (1973). Simple methods for plating single vegetative cells of, and for replica plating, filamentous blue-green algae. Archiv für Mikrobiologie 91, 91-95.

Wolk, C. P., Vonshak, A., Kehoe, P. \& Elhai, J. (1984). Construction of shuttle vectors capable of conjugative transfer from Escherichia coli to nitrogen-fixing filamentous cyanobacteria. Proceedings of the National Academy of Sciences of the United States of America 81, 1516-1565.

ZimMERMAN, F. K. (1977). Genetic effects of nitrous acid. Mutation Research 39, 127-148. 